\title{
A FILOSOFIA HERMENÊUTICA PARA UMA JURISDIÇÃO CONSTITUCIONAL DEMOCRÁTICA: FUNDAMENTAÇÃO/ APLICAÇÃO DA NORMA JURÍDICA NA CONTEMPORANEIDADE
}

Valéria Ribas do Nascimento

THE HERMENEUTICS PHILOSOPHY FOR DEMOCRATIC JURISDICTION.

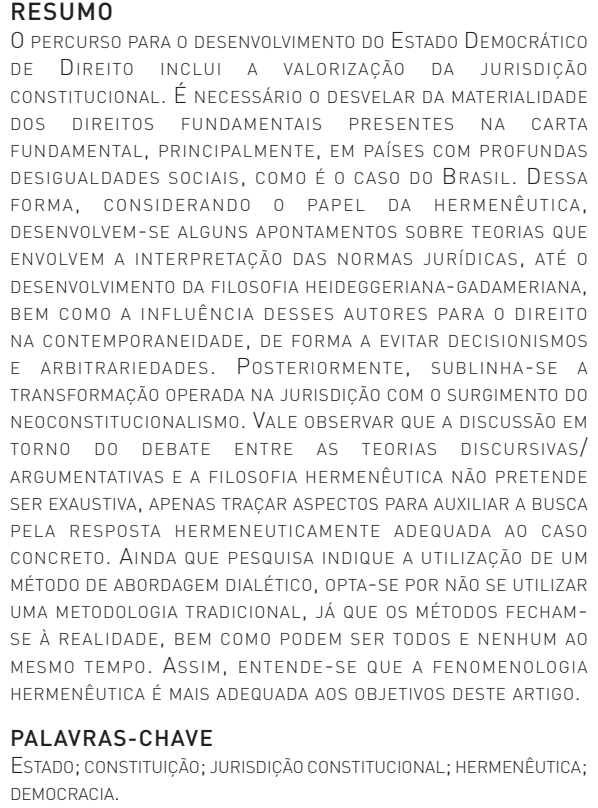

ESTADO; CONSTITUIÇÃO; JURISDIÇÃO CONSTITUCIONAL; HERMENÊUTICA; DEMOCRACIA.

\section{ABSTRACT}

THE PATH TOWARDS THE DEMOCRATIC RULE OF LAW'S STATE INCLUDES THE NEED FOR EMPHASIS OF CONSTITUTIONAL LAW. IT'S NECESSARY TO REMOVE THE VEIL OFF OF THE FUNDAMENTAL RIGHTS PRESENT IN THE CONSTITUTION, ESPECIALLY IN COUNTRIES WITH PROFOUND SOCIAL INEQUALITIES, SUCH AS BRAZIL. IS THIS MANNER, TAKING IN CONSIDERATION THE ROLE OF HERMENEUTICS, SOME NOTIONS THAT INVOLVE RULE OF LAW INTERPRETATION ARE DEVELOPED, INCLUDING THE PROGRESS OF THE HEIDEGERIAN-GADAMERIAN PHILOSOPHY, AS WELL AS THE INFLUENCE OF THESE AUTHORS TO CONTEMPORARY LAW, AS A WAY TO AVOID EARLY DECISIONS AND ARBITRARINESS. IN SEQUENCE, THE TRANSFORMATION SUFFERED BY JURISDICTION WITH THE ADVENT OF NEO CONSTITUTIONALISM IS HIGHLIGHTED. IT IS IMPORTANT TO NOTE THAT THE DISCUSSIONS CONCERNING THE DEBATE BETWEEN THE DISCURSIVE/ARGUMENTATIVE THEORIES AND HERMENEUTICS ARE NOT MEANT TO BE FINAL, ONLY TO TRACE ASPECTS IN ORDER TO HELP THE SEARCH FOR THE BEST SUITED HERMENEUTICS ANSWER IN EACH CASE. SHOULD THE RESEARCH POINT TOWARDS A DIALECTICIAN APPROACH, A TRADITIONAL METHODOLOGY WON'T BE USED, SINCE THE METHODS ARE CLOSED TO REALITY AND CAN BE ALL AND NONE AT THE SAME TIME. THEREFORE, WE SEE THAT PHENOMENOLOGY HERMENEUTICS IS THE BEST SUITED FOR THE GOALS OF THIS ARTICLE.

\section{KEYWORDS}

STATE; CONSTITUTION; CONSTITUTIONAL JURISDICTION: HERMENEUTICS; DEMOCRACY. 
"Eu dizia que o mundo é absurdo, mas ia muito mais depressa. Este mundo não é razoável em si mesmo, eis tudo que se pode dizer. Porém o mais absurdo é o confronto entre o irracional e o desejo desvairado de clareza cujo apelo ressoa no mais profundo do homem. O absurdo depende tanto do homem quanto do mundo. Por ora, é o único laço entre os dois."

Albert Camus, O Mito de Sísifo

\section{CONSIDERAÇÕES INICIAIS}

A importância das chamadas divindades de Olimpo que embasaram as religiões da Grécia e Roma antigas, atualmente, não pertencem ao âmbito da teologia, mas à literatura, arte, poesia, ou seja, busca-se através do retorno à mitologia o resgate ao imaginário. Este, na contemporaneidade, muitas vezes, encontra-se aprisionado pelos paradigmas metafísicos desenvolvidos no decorrer da história. Nos dois capítulos deste artigo, citam-se, metaforicamente, Jano e Sísifo. A primeira personagem manifestando duas cabeças e, aparentemente, a possibilidade de dois lados a seguir, enquanto a segundo retrata a lenda da condenação de um homem em carregar uma pedra morro acima. As perguntas que giram em torno da relação de Jano com a busca pelo sentido na Constituição, ou da relação de Sísifo com o papel do intérprete na teoria hermenêutica, serão desenvolvidas no decorrer deste texto. Todavia, importa destacar, desde já, o objetivo de demonstrar a relação da hermenêutica com a jurisdição e vice-versa, em um processo recíproco de desvelamento, a fim de se levar a sério a análise dos casos concretos.

Por isso, na primeira seção desenvolve-se a trajetória da hermenêutica na superação da filosofia da consciência - teoria que procurou transformar o direito em uma ciência lógica e exata. Entretanto, o direito é uma ciência social aplicada, ou melhor, uma ciência histórica em constante modificação, por isso, foi necessário à superação do paradigma vigente no Estado Moderno. Dessa maneira, no século XX, surge a hermenêutica heideggeriana-gadameriana, em que se observa o "método" fenomonológico, como um binômio velamento/desvelamento ou, em outras palavras, como um círculo hermenêutico, que evidencia a compreensão implicada em um dar-se conta da própria condição humana.

Levando em consideração essa teoria objetiva-se traçar alguns aspectos desenvolvidos por Lenio Luiz Streck, ao interpretar Heidegger e Gadamer, que podem auxiliar a jurisdição constitucional na fundamentação/aplicação das normas jurídicas.

Na segunda seção procura-se apontar o novo enfoque trazido pelo constitucionalismo do pós-guerra e o crescente processo de juridicização da Constituição, ou seja, o aumento do papel da Justiça Constitucional na implementação de políticas públicas e efetivação dos direitos fundamentais constitucionais. Pretende-se conduzir a dupla estrutura da linguagem presente na hermenêutica filosófica até a jurisdição constitucional, como forma de efetivação da materialidade constitucional. 
Salienta-se que as críticas desenvolvidas em torno das teorias discursivas/argumentativas de cunho procedimental, que são abordadas no decorrer do texto, de forma alguma, têm a pretensão de esgotar a matéria, tendo em vista a complexidade e diversidade de enfoques abordados por diferentes autores que tratam do tema.

\section{DA HERMENÊUTICA À JURISDIÇÃO CONSTITUCIONAL: JANO E A BUSCA PELO SENTIDO NA CONSTITUIÇÃO}

Ao lançar o olhar para a Grécia e Roma antigas retoma-se a imagem e a importância das divindades, tanto em produções de poesia como de belas artes, antigas e modernas. Dentre as divindades romanas, estava Jano, que era considerado o porteiro do céu. Era ele que abria o ano, resultando assim, até hoje, a nomenclatura do primeiro mês anual. Como divindade guardiã das portas, era geralmente apresentado com duas cabeças, pois todas as portas se voltam para dois lados (BULFINCH, 2003, p. 17). Considerando a importância da interpretação e da busca pela resposta adequada à Constituição é importante perceber que entre os dois lados de Jano, haverá o lado que levará a "verdade", sob o ponto de vista transcendental, ou seja, uma atitude cognitiva ao fenômeno convergente, que leve a resposta hermeneuticamente ${ }^{1}$ adequada e fundamentada ao caso concreto.

Peter Häberle (2008, p. 123) demonstra que o conceito de verdade é um valor cultural para o Estado Constitucional, principalmente após as experiências com o modelo totalitário; logo, é indispensável o estudo dessa temática na contemporaneidade. Não se trata de uma ilusão pela busca do "método", desenvolvido pelas ideias de Descartes e dos iluministas do século XVIII, que objetivava a certeza dos raciocínios matemáticos, mas é necessário que haja a estranhamento em face da constatação de que casos diferentes não exigirão respostas iguais, ou que casos iguais possam ter respostas diferente. É necessário que a angústia do estranhamente, desenvolvida por Martin Heidegger, ${ }^{2}$ leve ao alinhamento de projetos compreensivos.

Nesse sentido, na busca de novos caminhos, a sociedade passa por transformações contínuas ao longo da história. Com a formação do Estado Moderno ${ }^{3}$ rompeu-se a dominação medieval e a fragmentação do poder foi, gradativamente, substituída pela institucionalização do poder, o que implicou o abandono das doutrinas filosóficas vigentes até o momento. O paradigma da verdade baseado na fé em Deus, passou a ser o da verdade baseada na razão. Nessa sequência, o Estado assume uma roupagem absolutista, posteriormente liberal, até chegar ao Estado contemporâneo e suas diversas faces (Estado Social e Estado Democrático de Direito).

No âmbito dessas reflexões, interessa notar a importância da teoria hermenêutica, que busca traduzir para uma linguagem acessível aquilo que não é compreensível. Essas considerações demonstram a íntima relação entre Direito e linguagem, pois sempre existe uma tensão entre o texto proposto e o sentido que alcança a sua aplicação na 
situação concreta (STRECK, 2007, p. 126). Nas palavras do próprio Gadamer: "O homem somente conhece o texto, porque é um ser histórico" (2003, p. 311).

Assim, a discussão acerca da crise do conhecimento e do problema da fundamentação, própria da filosofia da década de 1920, é também a demonstração da revolução copernicana $a^{4}$ que atravessa o direito a partir do segundo pós-guerra. O problema que gira em torno da construção de um caminho capaz de dar conta do sentido de um discurso de interpretação dos textos legislativos é fundamental para o acontecer de uma jurisdição constitucional apta a efetivar os direitos fundamentais da pessoa humana, essenciais para um Estado verdadeiramente democrático.

\section{I.I A TRAJETÓRIa DA HeRmenêUTICA NA SUPERAÇ̃̃o DA FILOSOFIA DA CONSCIÊNCIA}

A explicação etimológica que gira em torno de hermènêus e da hermèneutike é relacionada, em regra, com o deus mediador Hermes, portador da vara mágica que possibilitava aos humanos compreender os desígnios divinos. Surge, assim, a ideia de um mensageiro divino, que transmite e esclarece o conteúdo da mensagem dos deuses aos mortais. Na realidade, não se sabia o que os deuses tinham dito, somente, se sabia o que Hermes dizia acerca do que os deuses previam. Daí aparece a (inter)mediação. Dessa maneira, Streck $(2007$, p. 126, 127) refere que é na metáfora de Hermes que se localiza toda complexidade do problema hermenêutico, pois trata de como dar sentido às coisas.

Laurence Tribe e Michael Dorf (2007), levando em consideração essa constante atribuição de sentido e o papel da hermenêutica constitucional, rejeitam qualquer teoria originalista da Constituição. Os autores americanos defendem a interpretação das normas jurídicas constitucionais e das categorias jurídicas como proteção substantiva dos direitos fundamentais. Por isso é necessário encontrar princípios de interpretação que possam colocar a Constituição em uma realidade mais segura e determinada.

O desenvolvimento da reflexão em torno da hermenêutica traz a assinatura da modernidade. Todavia, diferentes concepções podem ser seguidas retroativamente na antiguidade. Ao lado dos racionalistas eletas e platônicos existia uma série de sofistas relativistas, os quais tinham conhecimento de perspectivas humanas relacionadas ao poder. É, pois, questionável, até onde a história da hermenêutica deva recuar no passado. A resposta depende do que se pretende entender por hermenêutica (GRONDIN, 1999 , p. 47-48). O primeiro autor a apresentar essa ampliação quanto à pretensão de universalidade da hermenêutica foi Dannhauer, sendo também o primeiro a empregar a palavra hermenêutica. $\mathrm{O}$ seu programa filosófico encontrou numerosos seguidores no racionalismo dos séculos XVII e XVIII, como, J. Clauberg, J. E. Pfeiffer, J. M. Chaldenius e G. F. Meier. Igualmente, no iluminismo não faltaram hermenêuticas especiais (GRONDIN, 1999, p. 97, 98).

Não se pode deixar de mencionar que o nominalismo (conceptualismo) de Hobbes e de Locke é de fundamental importância para a questão política relacionada 
à emergência das teses contratualistas acerca do Estado. Essas teorias mediaram o rompimento da possibilidade da existência de essências e verdades imanentes. O especial lugar que concederam à linguagem e sua posição contrária à existência de universais tornaram-se importantes instrumentos para o rompimento com os dualismos metafísico-essencialistas. Não é temerário dizer que as teses nominalistas abrem os caminhos para o triunfo da viragem linguística ocorrida no século $X X$. Entretanto, sublinhase que Hobbes e Locke estavam diretamente influenciados pelas noções metafísicas, repletas de raciocínios matemático-dedutivos.

Nesse viés, a Idade Moderna foi marcada por um relevante momento histórico, iniciado no século XVIII, que se denominou iluminismo, ou "Século das Luzes". Na época ocorreu a predominância do progresso das ciências matemáticas e da técnica e a emancipação das ciências humanas da filosofia. Mas, ao mesmo tempo, o iluminismo produziu uma visão unilateral, pois estabelecia que a razão seria a única explicação para as coisas do universo. Isso caracteriza um retorno à metafísica, produzindo um constrangimento para o tipo de inventividade que justamente a tradição hermenêutica e a tradição filosófica tentam estabelecer (STEIN, 1996, p. 41).

A filosofia do direito aparece como título e sistematicidade na obra de Hegel. Todavia, por maior que exista um salto hegeliano na questão do direito, ele pensa as ciências jurídicas como um sistema absoluto. Ernildo Stein (2007, p. 101) afirma que no pensamento dialético a linguagem coincide com o objeto e o direito é exposto, não sendo interpretado, ou seja, na exposição dos sistemas dialéticos, a hermenêutica é apenas um apêndice.

Depois de Hegel, iniciou-se uma série de movimentos filosóficos, marcados pelo clima de transformação da revolução industrial. A filosofia via-se envolvida por uma sociedade progressivamente transformada por novas formas de convívio, novos valores, novas teorias sobre psicologia, religião e a história sobre o papel dos novos tipos de homens (STEIN, 2007, p. 102). Nesse contexto de fim das filosofias, surgiram, por volta de 1850 , indivíduos como Marx e Darwin e um pouco mais tarde, Freud e Nietzsche. Aparentemente, a segunda metade do século XIX, apresentava a filosofia sem novidades, mas as transformações eram profundas. Depois de Hegel se volta a Kant, através do chamado neo-kantismo, e se passa à busca de alternativas contra o materialismo pela escola histórica alemã. (STEIN, 2007, p. 102).

O neo-kantismo percebia o direito como uma defesa da moral e do Estado. Não mais se buscava a razão, mas a defesa dos princípios e valores para justificar o direito. Era o começo do positivismo com regras e técnicas de interpretação, buscando-se um rigor lógico-dedutivo. Cita-se, ainda, a escola histórica alemã, com Ranke, Troeltsch, Dilthey, entre outros, que introduziria uma teoria da história, com certas hipóteses para encontrar o estatuto legitimador das ciências humanas (STEIN, 2007, p.102, 103).

As crises pela qual passava a filosofia da época são o pano de fundo para o surgimento da fenomenologia, com Husserl, na década de 1910. Posteriormente, Heidegger 
radicaliza a hermenêutica, como será demonstrado a seguir. É importante destacar que a teoria desenvolvida por Streck, atualmente no Brasil, denominada de Crítica Hermenêutica do Direito (CHD) ou Nova Crítica do Direito (NCD), ${ }^{5}$ tem como base justamente a desconstrução da metafísica vigorante do pensamento dogmático do direito, na modernidade também denominada de teoria do conhecimento (filosofia da consciência). Assim, reintroduzindo o direito no domínio das ciências da compreensão é possível recuperar sua função social e democrática. No decorrer destas reflexões objetiva-se demonstrar a importância da hermenêutica filosófica na elaboração de uma análise antimetafísica da jurisdição constitucional.

\section{I.2 A HERMENÊUTICA HEIDEGGERIANA-GADAMERIANA E A COMPREENSÃo NA JURISDIÇÃO CONSTITUCIONAL}

Martin Heidegger (1889-1976), um dos principais filósofos do século XX, deixou uma produção bibliográfica que ultrapassa mais de cem volumes. Para Rüdiger Safranski (2000, p. 18), as obras do filósofo formam capítulos excitantes da história, sendo necessário falar dele no bem e no mal, e além do bem e do mal.

O pensamento de Heidegger deve ser analisado a partir do momento histórico em que o mesmo se encontrava, pois no início do século XX iniciava-se na Europa uma espécie de desestruturação do pensamento filosófico. Na verdade, depois da crise das teorias ligadas ao pensamento absoluto, inicia-se uma espécie de desagregação do pensamento filosófico. Essa desagregação se deve em parte ao surgimento das ciências humanas que começavam a se afirmar com autonomia. Com efeito, foi o campo ideal para o retorno das teorias do conhecimento, chamadas de epistemologias. Entre elas, duas se sobressaem: a da lógica e a da linguagem, sendo que esta não aceitava explicações puramente científicas, destacando-se a fenomenologia de Edmund Husserl. No momento em que Heidegger observa a fenomenologia percebe que está diante da possibilidade do recomeço da filosofia, a qual se afasta da metafísica aprisionada ao esquema sujeito-objeto e visa a situação concreta do homem (STRECK, 2006, p. 425).

A análise de Heidegger é consagrada à questão do ser. Assim, em 1927, lança Ser e tempo, considerado um dos mais importantes livros da atualidade, em que consta a provocação em torno da ontologia fundamental ${ }^{6}$ como analítica existencial. Importa referir que durante o desenvolvimento das demais obras de Heidegger ocorre o fechamento de alguns ciclos e a abertura de novos. Dessa forma, Gianni Vattimo (1996, p. 109-110) aborda três momentos da filosofia heideggeriana. Primeiro ciclo até a verificação de Ser e tempo. Dessa obra surgem algumas indagações como: o problema da diferença ontológica, do nada e da verdade, o que leva ao "segundo" Heidegger a reconstruir a história da metafísica e o "terceiro" a buscar uma compreensão não metafísica do ser. Salienta-se que os três momentos supõe um fio condutor unitário de aprofundamento dos temas abordados em sua grande obra (STEIN, 2004, p. 28). 
Dessa maneira, para se compreender a linguagem, é indispensável contextualizála. As proposições dependem da situação histórica, cultural e do viés subjetivo. Heidegger recomendava ao ser humano estabelecer-se radicalmente ao nível da finitude, elaborando a própria estrutura preconceituosa como estrutura positiva e ontológica da compreensão, para perceber as próprias possibilidades, a partir da situação existencial. Recuperou o questionamento epistemológico do historicismo, ${ }^{7}$ buscando um dar-se conta do ser-no-mundo, ou ser-aí (Dasein). ${ }^{8}$

Durante a década de 1930, vai tomando forma o movimento de ir além do projeto de Ser e tempo, denominado por Heidegger de Kehre, de viravolta. Nessa fase, ele indica o pensamento que põe o problema do ser mais além (meta) do ente como tal. Afirma que a metafísica está conaturalizada com o próprio estar-aí do homem (HEIDEGGER, 1991). Já, o Heidegger III procura afastar as cortinas com que se fecha o verdadeiro cenário do ocidente (STEIN, 2004, p. 27). Grande parte da obra publicada a partir do fim da década de 1940 poderia ser considerada um diagnóstico dos fenômenos fundamentais da segunda metade do século XX. Trabalhando com a questão da linguagem, da técnica, arte, poesia, pensamento, dentre outras, Heidegger retoma o seu pensamento para apresentar respostas aos problemas postos pela humanidade. Nesse sentido cabe lembrar que o direito se rege pela palavra. É interpretando a palavra escrita na lei que se faz a justiça do caso concreto.

Quanto ao filósofo Hans-Gerg Gadamer (1900-2002), pode-se dizer que ele é conhecido por várias obras, dentre elas está o livro Verdade e método. Gadamer destacava-se pela simpatia e humildade, além do enorme e indiscutível conhecimento filosófico. O autor detalhando os estudos de Heidegger buscou humanizá-lo. Ao completar 102 anos, disse a um jornalista da agência alemã DPA: "Queres saber uma coisa? O que eu penso não é tão importante. A única frase que quero defender sem restrição é que os seres humanos não podem viver sem esperanças" (GADAMER, 2002).

$\mathrm{Na}$ obra Verdade e método, que pode ser lida "Verdade contra método", desenvolve-se o acontecer da verdade, no qual sempre está presente a tradição. Evidencia-se a possibilidade de explicar fenomenologicamente esse acontecer em três esferas da tradição: na obra de arte, na história e na linguagem. A hermenêutica que cuida dessa verdade não se submete a regras metódicas das ciências humanas, por isso ela é chamada de hermenêutica filosófica. Assim, Gadamer inaugura um lugar para atividade da razão, fora das disciplinas da filosofia clássica e num contexto em que a metafísica foi superada (STEIN, 2007).

Gadamer retoma o diálogo com as ciências humanas, não para trabalhar essencialmente uma metodologia hermenêutica, mas, sim, para realçar a insustentabilidade da ideia de um conhecimento universalmente válido e o questionamento do historicismo. A controvérsia do historicismo, tangenciada por Heidegger, torna-se labor central para Gadamer (2003, p. 37-44), sendo que este reconstrói a estrutura ontológica do círculo hermenêutico heideggeriano. Destaca-se que a categoria do círculo hermenêutico, 
ou do sentido reduplicado, é de fundamental importância para o direito e para jurisdição constitucional, pois a premissa filosófica demonstra que a história, a cultura e a tradição já estão na estrutura de compreensão do intérprete, formando uma circularidade (STEIN, 1996, p. 42). Isso sublinha a necessidade de fundamentação do julgador para se atingir a resposta hermeneuticamente adequada em cada processo.

É patente na leitura gadameriana a fundamentação vinculada à lógica de perguntas e respostas, ou seja, o fenômeno hermenêutica implica o caráter original da conversação na busca pelo sentido, no acontecer da verdade através da linguagem (GADAMER, 2003, p. 482). Somente se alcança a verdade do texto ao perguntar, ao analisar os argumentos apresentados no caso concreto.

Outro aspecto central da hermenêutica gadameriana é a questão da aplicação. Assim como Heidegger, Gadamer entende que compreender é sempre um compreender-se, e não reproduzir, mas, sobretudo, aplicar. Entender um texto do passado também implica trazê-lo para o presente. Relacionando a filosofia e o direito, Gadamer afirma que o saber acerca do direito e dos costumes sempre será completado através do caso particular. O juiz não apenas aplica a lei em concreto, mas colabora ele mesmo, através de sua sentença, para a evolução do direito (direito judicial). Assim, como o direito, também os costumes aperfeiçoam-se por força da produtividade de cada caso particular (GADAMER, 2003, p. 79). Dessa maneira, é ressalvada a importância da análise individual, fática, de cada caso em concreto, pois não se pode afirmar que o juízo só seja produtivo, mas, ao contrário, deve-se reconhecer a produtividade do juízo.

Segundo a filosofia gadameriana, o ser que se pode compreender é linguagem. Essa frase não quer dizer o domínio daquele que compreende sobre o ser, ao contrário, significa que o ser não é experimentado, assim algo pode ser construído (GADAMER, 2003, p. 612). Nessa lógica, concebe compreensão como poder de disposição, ou como participação em um significado, em uma tradição, enfim, em uma conversação. Não existe enunciado afirmativo, mas um ato em transformação.

Com Stein sublinha-se que, em Heidegger, a hermenêutica é adjetivo e em Gadamer, substantivo, o que revela uma diferença fundamental entre os dois autores. Para Gadamer a intenção ontológica se dirige para a nunca recuperável historicidade do compreender que é uma experiência fática em todo universo das ciências humanas (STEIN, 2007, p. 78).

A hermenêutica realiza a interpretação da faticidade humana, que tenta prestar contas da sua finitude como a do horizonte universal, a partir da qual tudo pode fazer sentido. Vislumbra-se sua importância não só como forma de interpretação das regras jurídicas, mas também como uma forma de adequá-las às constantes modificações sociais. $\mathrm{O}$ atual momento em que se encontra o direito constitucional necessita de meios para adquirir efetividade. Nesse passo, verifica-se a utilização da hermenêutica, que trabalha com o dar sentido ao texto jurídico, com o Dasein (ser-aí). Essa nova forma de exegese busca retirar o véu que encobre os operadores jurídicos, objetivando o 
“des" velamento (alétheia) ${ }^{9}$ da aplicação do Direito ao caso em concreto. Deve-se deixar claro que os momentos de fundamentação e aplicação das normas jurídicas não devem ser percebidos de forma separada, mas como processos interligados e contínuos, que evidenciem a situação histórica analisada.

Streck (2007, p. 82-83) demonstra que não surpreende aos juristas que, até a poucos anos, alguns tribunais sustentavam que o marido não podia ser sujeito ativo em estupro cometido contra a esposa, por lhe caber o exercício regular do direito. Com efeito, a ficcionalização do "mundo jurídico" em que ainda se utiliza como exemplo pensonagens comuns nas culturas dos manuais, vai levar à formação de juristas sem consciência crítica, de operadores jurídicos sem capacidade de perceber a realidade e a necessária importância da preservação dos princípios da dignidade humana e da igualização em sociedade, valores fundamentais do Estado Democrático de Direito.

Diante do quadro de enfraquecimento ou esvaziamento da relação entre a legislação e a realidade, constata-se a relevância da hermenêutica, pois, paulatinamente, aconteceu um efetivo crescimento no grau de deslocamento do polo de tensão entre os poderes do Estado em direção à jurisdição constitucional pela impossibilidade do legislativo de poder prever todas as hipóteses de aplicação. A chamada jurisprudencialização da Constituição vem marcada pela transição de um direito constitucional legislativo para um direito constitucional jurisprudencial, ou seja, passa-se do texto da norma para o texto da decisão judicial. Tal posição leva a uma mudança de paradigma do constitucionalismo, antes pautado na postura positivista, para percebê-lo em sua forma aberta e viva, para além da neutralidade do texto normativo (BOLZAN DE MORAIS, 2006).

Entretanto, no momento em que crescem as ações por direitos fundamentais, aumenta a necessidade de se discutir limites a atuação do Poder Judiciário na interpretação da Constituição (STRECK, 2007, p. 1-2). Não é possível aceitar que o arbítrio de juízes solipsistas prevaleçam sobre a Constituição e a democracia. Para ilustrar até onde podem chegar as decisões arbitrárias, cita-se julgado proferido em caso envolvendo suposta discriminação por homossexualidade.

O caso trata de uma queixa-crime, proposta por um jogador de futebol. Na decisão, o magistrado refere: "Trazer o episódio à Justiça, outra coisa não é senão dar dimensão exagerada a um fato insignificante, se comparado à grandeza do futebol brasileiro". ${ }^{10} \mathrm{Com}$ a devida vênia, a sentença está repleta de preconceito contra homossexuais, cidadãos brasileiros, que possuem direitos fundamentais assegurados na Constituição de 1988 . A arbitrariedade da sentença continua:

[...] Ora bolas, se a moda pega, logo teremos o SISTEMA DE COTAS, forçando o acesso de tantos por agremiação... E não se diga que essa abertura será de idêntica proporção ao que se deu quando os negros passaram a compor equipes. Nada menos exato. Também o negro, se homossexual, deve evitar fazer parte de equipes futebolísticas de héteros (destaque do original). ${ }^{11}$ 
Pode-se perceber através da fundamentação as pré-compreensões do julgador, tanto com relação ao sistema de cotas, como no tocante à cor da pele. Na continuação da sentença dispõe que "não se mostra razoável a aceitação de homossexuais no futebol brasileiro porque prejudicaria a uniformidade do pensamento da equipe, o entrosamento, o equilíbrio, o idea [...]" O grau de discriminação chega ao auge quando afirma que a presença de homossexuais causa o "desconforto do torcedor, que pretende ir ao estádio com seu filho". Para finalizar, ainda ressalta que: "É assim que eu penso... e porque penso assim, na condição de Magistrado, digo!". ${ }^{12}$

Com o disposto no caso ora elencado, sublinha-se até que ponto pode chegar a arbitrariedade de juízes "iluminados" e solipsistas. Daí ser imprescindível o estudo da hemenêutica da faticidade, que para além da importância do caso concreto, destaca a diferença ontológica e o círculo hermenêutico como fundamentos da interpretação. Aquela expressão relaciona-se ao fato de que a busca pelo conhecimento não deve se dar de forma isolada, em uma entidade, como alto externo, mas, sim, através da relação observado/observador, na "diferença” entre os dois. Já, o círculo hermenêutico, como foi mencionado anteriormente, aparece na medida em que "somos mundo e ao mesmo tempo projetamos mundo. Estamos envolvidos com os objetos do mundo e descrevemos o mundo no qual se dão os objetos" (STEIN, 2006, p. 61). Em outras palavras, a hermenêutica filosófica demonstra a necessidade de a jurisdição observar a situação histórica, cultural e social das partes envolvidas.

Com Streck (2007, p. 6, 7), destaca-se que o pós-positivismo deve ser entendido como superação, como um constitucionalismo compromissário e transformador surgido no pós-guerra, que é aquilo que vem sendo denominado de neoconstitucionalismo. Por tudo isso, há uma incompatibilidade entre o novo constitucionalismo e as várias formas de positivismos, teorias ainda aprisionadas à separação sujeito-objeto.

Não se discute a importância do Poder Judiciário no Estado Democrático de Direito, tendo em vista que a função de aplicar a legislação é um fator de transformação social, um instrumento de realização dos direitos fundamentais, de implementação de políticas públicas e de diálogo entre as partes do processo. Todavia, o fenômeno do neoconstitucionalismo, em que o Poder Judiciário ocupa papel de destaque, necessita de meios para a obtenção de respostas constitucionalmente adequadas com o sentido material da Constituição, pois a ocorrência de arbitrariedades vai de encontro à democracia.

O debate que gira em torno do papel da jurisdição constitucional - da escolha entre respostas conteudísticas e procedimentais ou, se quiser, entre verdade contra consenso ${ }^{13}$ - é de grande importância para o direito como um todo, pois o direito é linguagem e a linguagem necessariamente leva à interpretação. Por isso, na próxima seção pretende-se, por meio do fio condutor da hermenêutica da faticidade, abordar uma jurisdição constitucional apta a buscar respostas adequadas à materialidade da Constituição. Também, serão elencadas algumas discussões referentes às críticas que a filosofia hermenêutica têm recebido das teorias discursivas e argumentativas. 


\section{DA JURISDIÇÃo CONSTITUCIONAL À HERMENÊUTICA DA FATICIDADE: SÍSIFO E O ACONTECER DE UM DISCURSO CONSTITUCIONAL DEMOCRÁTICO} A lenda de Sísifo vem marcada pela imagem do homem condenado a arrastar uma rocha morro acima, e que sempre despenca tão logo ele chega ao topo. No entanto, esse é apenas o fim da história da vida de Sísifo. Antes disso, a personagem é conhecida como a mais astuta dos mortais, chegando até mesmo a enganar a morte, deixando-a presa, o que teria despovoado o inferno. A narrativa também é marcada por várias vitórias, como conquistas de cidades, até ele se tornar rei. Mas, um dia, a vida de Sísifo chegou ao seu termo, como a de todos os mortais. Júpiter resolve puni-lo por suas afrontas. Sísifo foi então levado a Tártaro e condenado a rolar uma enorme pedra até o todo de uma montanha. Tão logo chega ao cume, ela despenca, obrigando-o a recomeçar o trabalho, que se repete para sempre (BRANDÃO, 2000, p. 430-431).

Albert Camus (2006, p. 141), ao escrever sobre o homem absurdo e trazer o mito de Sísifo, entende que no instante sutil em que o homem se volta para o seu destino, percebe que foi criado por ele próprio, unido pela memória e em breve selado pela morte. Dessa maneira, a condenação de empurrar incessantemente a rocha até o alto de uma montanha, de onde tornava a cair por seu próprio peso, possui origem humana e tudo o que é humano sempre está em marcha.

Dos comentários sobre a narrativa de Sísifo, pode-se reter, entre tantas outras, duas ideias-chave para o direito e a para a jurisdição constitucional. A primeira permite reconhecer que a personagem lutava por seus objetivos, com isso, venceu muitas batalhas durante a vida. Ora, disso retira-se que o homem, como ente privilegiado, consegue transformar sua própria condição de ser-no-mundo, sendo responsável por seu destino. Para pensar o presente e o futuro é inolvidável estudar o papel do Estado e dos textos legais que regem as relações sociais. Assim, necessita-se de condições seguras para interpretação da legislação para se atingir a justiça na fundamentação/aplicação da norma jurídica. A segunda ideia é de que tudo que é humano sempre está em movimento, por isso a relevância de pesquisas referentes à linguagem e a interpretação. Ora, se a jurisdição constitucional caracteriza-se pela constante aplicação da Constituição como parâmetro nas decisões judiciais, é indispensável que se verifiquem alguns limites de atuação.

Segundo Gadamer (2003, p. 436), o "que há de verdadeiramente comum a todas as formas de hermenêutica é que o sentido que se deve compreender somente se concretiza e se completa na interpretação". A ação interpretadora se mantém totalmente ligada ao sentido do texto. Nem o jurista e nem o teólogo consideram a tarefa da aplicação como uma liberdade frente ao texto.

O filósofo alemão é claro ao afirmar que compreender uma ordem ou um mandamento significa aplicá-la à situação concreta a que se refere. Por isso não há dúvida de que o receptor tem de levar a cabo um certo desempenho produtivo na busca pelo sentido. A questão que envolve as condições interpretativas capazes de garantir a resposta 
adequada diante da indeterminabilidade do direito e da crise de inefetividade da Constituição é uma preocupação crescente na contemporaneidade. A hermenêutica fenomenológica aplicada pela jurisdição constitucional pode levar de uma postura metafísica para uma verdadeira compreensão da materialidade constitucional. A seguir procura-se traçar alguns dilemas que têm enfrentado a jurisdição constitucional até a inserção da hermenêutica filosófica.

\section{I A CONSTRUÇÃo Da JURISDiÇão CONSTITUCIONAL E A HERANÇA DE UM MODELO FORMAL/MATERIAL}

O termo Constituição ${ }^{14}$ consagrou-se com os americanos, na Revolução de 1776/1787 e, posteriormente, na Revolução Francesa de 1789, sendo que esta deu sua contribuição para todo Ocidente contemporâneo (SALDANHA, 2000, p. 118-119). Assim, o constitucionalismo surge como uma teoria normativa da política, ou, em outras palavras, uma forma de submeter o poder político ao Direito, limitar suas funções, garantir o direito de liberdade aos cidadãos e estabelecer a separação dos poderes. $\mathrm{O}$ aparecimento das Constituições, e a sua importância para a instituição e manutenção da democracia, representou verdadeira revolução, baseada no fato de que a Constituição representava afirmação da coletividade e, em razão disso, subordinadora do Estado (MOREIRA, 2001, p. 314-318).

A mudança de modelo de Estado, até então absoluto, centrado na pessoa e na vontade do príncipe, passou a curvar-se à Constituição, para, através dela, legitimar o poder do Estado. Com isso, pretendeu-se proteger os direitos da pessoa humana. Salienta-se o fato de que os ideais do mundo novo, surgido "pós" Revolução Francesa, estavam inebriados pelos princípios racionalistas cartesianos. Dessa forma, o exercício da jurisdição servia para alimentar e concretizar tais perspectivas, na medida em que se buscava a satisfação da classe liberal burguesa do final do século XVIII e início do XIX. Esse foi o período do Estado de Direito, baseado na submissão dos governos à lei. Acontece que a ideia de um Estado mínimo que, de forma alguma, interviesse na vida dos indivíduos não foi suficiente. No final do século XIX e início do XX, foi necessário dar-lhe uma dimensão social, inserido-lhe o ideal democrático. Desencadeou-se, então, o processo de democratização do Estado, no qual, além da submissão à lei, deveria haver a supremacia da vontade popular.

Para Lenio Luiz Streck (2006, p. 93-94) e José Luis Bolzan de Morais, “o Estado Democrático de Direito teria a característica de ultrapassar não só a formulação do Estado Liberal de Direito, como também a do Estado Social de Direito”. Com isso, impõe-se à ordem jurídica e à atividade estatal um conteúdo de transformação da realidade, o que se poderia denominar de plus normativo em relação às transformações anteriores. Outrossim, com as mudanças ocorridas no Estado, também as Constituições sofreram modificações. Vale referir que, enquanto o Estado Liberal optava por uma concepção de Constituição-garantia, que tinha a função de preservar 
o conjunto das liberdades individuais; o Estado Democrático (e Social) optou pela Constituição como um projeto social, integrado por um conjunto de valores compartilhados. Daí a ideia de Constituição-dirigente (CITTADINO, 2000, p. 246).

O constitucionalismo do Estado Democrático de Direito, além de evidenciar a tese do constitucionalismo comunitário, também trouxe a lume teorias como a da força normativa da Constituição, ${ }^{15}$ Constituição como cultura, ${ }^{16}$ Constituição aberta, ${ }^{17}$ bem como novos paradigmas de interpretação dos textos constitucionais. Essas questões implicaram uma espécie de intervencionismo dos tribunais constitucionais, denominado de judicialização da política. ${ }^{18}$

Dessa forma, as transformações ocorridas no constitucionalismo propiciaram modificações no papel que os juízes passaram a desempenhar na consolidação do modelo da democratização do Estado. Entretanto, a jurisdição constitucional, apresentando-se como uma forma de controle de constitucionalidade, pode evidenciar um sentido formal ou material. No primeiro, o controle é estritamente jurídico possuindo feição técnica, não perquirindo acerca do conteúdo ou substância da norma impugnada. O controle material, ao contrário, busca acomodar a regra jurídica ao espírito da Constituição e aos seus princípios (BONAVIDES, 2003, p. 299).

Destaca-se que, independentemente de o Brasil, atualmente, realizar um controle formal e material, é necessário indiscutivelmente a busca pelo controle material de constitucionalidade, porque a materialidade se refere ao conteúdo da regra e, somente assim, aparece a força normativa da Constituição. Com a Carta Fundamental de 1988, o sistema brasileiro (combinação do modelo difuso-incidental com o concentrado-principal) de fiscalização da constitucionalidade foi aperfeiçoado. A nova ordem constitucional: ampliou o número dos legitimados ativos para ingressar com a ação direta de inconstitucionalidade (art. 103), extinguindo o monopólio do Procurador-Geral da República; introduziu ação direta de inconstitucionalidade por omissão (art. 103, § $2^{\circ}$ ), o mandado de injunção (art. 102, I, q), a arguição de descumprimento de preceito fundamental (art. 102, $\S 1^{\circ}$ ); previu a inconstitucionalidade de leis e atos normativos estaduais ou municipais em face da Constituição estadual (art. 125); etc.

Ademais, a nova ordem constitucional tem dado especial relevância ao controle concentrado. Tanto é certa essa assertiva que foi estabelecida, através da Emenda Constitucional n. 3/1993, a ação declaratória de constitucionalidade (ADC), que consiste em típico processo objetivo, destinado a afastar a insegurança jurídica e o estado de incerteza sobre a validade de lei, ou ato normativo federal. Depois da inserção do efeito vinculante através da ADC, foram incorporadas, ainda, as legislações infraconstitucionais n. 9.868/1999 e 9.882/1999 que, da mesma forma, dispuseram sobre o efeito vinculante e sobre o alcance das decisões do STF, para além do conhecido efeito ex-tunc e ex-nunc. Importa referir que essa é uma "(i)legítima” criação brasileira, não existindo nos demais Estados Democráticos. 
Pode-se, ainda, citar como exemplo da abstrativação do controle de constitucionalidade a incorporação da súmula vinculante, através da Emenda Constitucional n. 45/2004, posteriormente regulamentada através da Lei n. 11.417/2006 e o Instituto da Repercussão Geral, efetivado com a Lei n. 11.418/2006, que estabelece a necessidade de comprovação de questões relevantes do ponto de vista econômico, político, social ou jurídico, que ultrapassem os interesses subjetivos da causa.

Pelo que foi exposto, percebe-se que o atual modelo de jurisdição constitucional adotado no Brasil vem gradativamente assumindo características que podem acarretar a impossibilidade de análise do caso concreto pelo Poder Judiciário. É necessário (re)visitar a hermenêutica da faticidade para se resgatar a necessária materialidade constitucional que deve estar presente no fundamento/aplicação dos discursos decisórios democráticos.

\subsection{O NEOCONSTITUCIONALISMO E A DUPLA ESTRUTURA DA LINGUAGEM PRESENTE NO} DISCURSO JURÍDICO DEMOCRÁTICO: RESGATE DA MATERIALIDADE CONSTITUCIONAL

Nos dias atuais, o papel da Constituição e sua força normativa, bem como seu grau de dirigismo estatal, dependerão da opção por um dos eixos temáticos que balizam a discussão em torno da linguagem. De um lado, as teorias procedimentais, que abarcam a teoria argumentativa e a teoria discursiva, e do outro, as teorias materiais-substanciais, onde se encontra a hermenêutica da faticidade. As teses materiais colocam em evidência a regra contramajoritária (barreira às vontades de maioria enventuais), o que reforçaria a relação Constituição-democracia, salientando-se que o processo e a jurisdição possibilitam o diálogo entre as partes, o que ressalta o caráter democrático da jurisdição constitucional. Para os procedimentalistas, no entanto, existe uma falta de legitimidade da justiça constitucional, o que coloniza o mundo da vida na acepção de Jürgen Habermas (STRECK, 2007, p. 24-25).

Ainda, percebe-se que Habermas (1997) critica fortemente a invasão da política e da sociedade pelo direito, buscando utilizar a distinção entre política e direito à luz da teoria do discurso. Dessa forma, o Judiciário como centro do sistema jurídico atua mediante discursos de fundamentação e discursos de aplicação, que demonstram uma atividade imparcial na aplicação do direito.

Marcelo Andrade Cattoni de Oliveira (2004, p. 55) refere que a noção de paradigma jurídico proposta por Habermas pretende estabilizar a tensão entre realidade e idealidade, ao reconhecer a existência de um horizonte histórico de sentido, que pressupõe uma determinada "percepção" do contexto social do direito. Assim, a partir dessa percepção o direito pode cumprir seu papel de redutor de complexidades. Isso retiraria do ombro do intérprete um encargo hercúleo.

Habermas (1997, p. 264) dispõe que a crise do paradigma liberal e do modelo de bem-estar social possibilitou o estabelecimento de uma compreensão reflexiva do direito. O autor desenvolve uma teoria do direito e da política à luz da teoria do discurso, 
pretendendo dar contornos nítidos a um terceiro paradigma, buscando uma compreensão procedimental do direito, ou seja, passa de uma postura excessivamente concretista para um viés de conexão entre autonomia privada e autonomia pública, a qual necessita ser interpretada caso a caso.

O filósofo, também, faz a distinção entre discursos de fundamentação e discursos de aplicação. Aqueles se referem à validade da norma, e se desenvolvem como o aporte de razões e formas de argumentação de um amplo espectro (morais, éticas e pragmáticas). Já os discursos de aplicação se relacionam à adequabilidade de normas válidas a um caso concreto, a serem argumentativamente problematizadas. (OLIVEIRA, 2004, p. 6263). Todavia, o questionamento que se faz é como separar planos de fundamentação e aplicação? Trazendo a baila à teoria hermenêutica de Heidegger e Gadamer ressalta-se a diferença ontológica e o círculo hermenêutico que revelam a dupla estrutura da linguagem, demonstrando a impossibilidade de separações metafísicas entre ser e ente.

Como já foi mencionado, enquanto na teoria discursiva há uma cisão entre discursos de fundamentação e aplicação (ressalta-se que os adeptos da teoria habermasiana negam essa separação), na hermenêutica da faticidade, interpretar é aplicar, isso quer dizer que entre fato e direito, entre ser e ente, há apenas uma diferença que é ontológica. Habermas, também faz severas críticas à leitura que Alexy realiza do modelo construtivo do direito de Dworkin que, de certa forma, teria acarretado o gigantismo ou politização do Judiciário no pós-guerra.

O modelo de democracia habermasiano não tem como condição prévia fundamentar-se nem em valores compartilhados, nem em conteúdos substantivos, mas em procedimentos que determinam a formação democrática da opinião e da vontade e que exigem uma identidade política. Logo, o papel das Cortes Constitucionais estaria restrito à tarefa de compreensão procedimental da Constituição, limitando-se a proteger um processo de criação democrática do direito, devendo zelar para que a cidadania disponha de meios para solucionar os problemas sociais.

Streck afirma que o problema fundamental das teorias procedimentais reside no fato de "procurarem colocar no procedimento o modo (ideal) de operar a democracia, a partir de uma universalização aplicativa”. Já os defensores das teorias substanciais da Constituição trabalham com a perspectiva de que a implementação dos direitos fundamentais evidenciam a condição de possibilidade de efetividade constitucional, percebendo a Constituição como elo conteudístico que une a política e o direito (STRECK, 2007, p. 26). Assim, o Poder Judiciário teria um papel central na aplicação dos direitos fundamentais, o que evidenciaria a relação direta com a democracia.

Salienta-se, com Gilberto Bercovici (2002), que o modelo substancialista, vai de encontro ao problema dos "ativismos judiciais", entendido como decisionismo, praticado a partir de discricionariedades interpretativas. A hermenêutica trabalha na perspectiva de que a Constituição estabelece as condições do agir político-estatal e, principalmente, a partir da $2^{\circ}$ Guerra, com a positivação dos direitos 
sociais/fundamentais, a jurisdição constitucional tornou-se um fator imprescindível na execução de políticas públicas e na preservação dos direitos fundamentais.

Por essas razões, há uma marcante diferença entre aquilo que tem sido chamado de ativismo judicial, ou jurisprudência dos valores, e a denominada Nova Crítica do Direito ou Crítica Hermenêutica do Direito, tendo como base teórica a filosofia de Heidegger e Gadamer. A tese desenvolvida por Streck (2007, p. 165-167) critica a metafísica, que, na modernidade, recebeu o nome de teoria do conhecimento ou filosofia da consciência. No campo jurídico, o paradigma dedutivista e objetificador afastou o direito da realidade, tornando-o refém do sistema, impedindo seu papel transformador.

A Nova Crítica do Direito objetiva, através de uma análise fenomenológica, o desvelamento daquilo que no comportamento cotidiano é ocultado, o exercício da transcendência, no qual não apenas aparece o ser, mas também o ser-aí, o ser-nomundo. O processo interpretativo deixa de ser reprodutivo e passa a ser produtivo, onde a linguagem deixa se ser um instrumento, uma terceira coisa que se interpõe entre sujeito e objeto, passando a ser condição de possibilidade.

Nesse viés, cita-se importante decisão do Supremo Tribunal Federal referente ao Mandado de Injunção n. 721-7, em que a Corte brasileira efetivou importante remédio constitucional voltado à implementação das normas de eficácia limitada. A impetrante, servidora do Ministério da Saúde, atuava em ambiente insalubre e evocou o disposto no art. $40, \S 4^{\circ}$, da Constituição Federal para ressaltar que a inexistência de lei complementar inviabilizava o direito à aposentadoria. Então buscou a supressão da lacuna normativa, o que foi concedido pela Corte brasileira. O Tribunal aplicou, supletivamente, o art. 57, da lei n. 8213/91, legislação utilizada para os trabalhadores em geral (Brasil, 05.06.2008). Pode-se observar uma atuação em prol dos direitos sociais fundamentais. Tendo como base o referencial teórico aqui adotado, é inexorável reafirmar que a hermenêutica combate toda e qualquer forma de decisionismos buscando levar a Constituição a sério.

Toda e qualquer decisão judicial deve perceber que acontece no interior de uma circularidade que se dá em uma espécie de espiral hermenêutica. Nessa espécie de espiral, a autocompreensão se desdobra e se produzem paradas. A lei é uma parada; a própria Constituição o é, em um nível superior, enquanto "matriz de sentido"(STRECK, 2006, p. 231 232). A Constituição, como fundamento de sentido do ordenamento, é um lugar no qual se dá o sentido fundamental do ordenamento. No entanto, o sentido entre texto e intérprete se dá em uma relação recíproca, em processo de circularidade e na observância da diferença ontológica.

Antes de discorrer sobre a crítica à teoria da "ponderação" de princípio de Alexy (1997, p. 81-115), vale observar algumas premissas desenvolvidas pelo doutrinador. Ressalta-se que abaixo do conceito de normas, estariam as regras e os princípios, mas a grande questão se encontra nos mecanismos de aplicação de normas principiológicas. 
Alexy admite como ponto de partida que o termo princípio não se contrapõe à norma, mas à regra, porque norma é o significado de um enunciado que diz que algo "deve ser", e como tanto as regras quanto os princípios expressam que algo "deve (juridicamente) ser", ambos precisam ser entendidos como tipos de normas jurídicas. Assim, para o autor a diferença entre princípios e regras não é quantitativa (não é a maior ou menor generalidade/abstração que diferencia ambas as categorias), mas qualitativa. (ALEXY, 1997, p. 81-115). Daí, princípios seriam normas de otimização, que poderiam ser obedecidas em diferentes graus, ao passo que as regras seriam normas que só poderiam ser cumpridas ou não. Em consequência, os princípios não conteriam mandados definitivos, mas somente prima facie. Pelo fato de se afirmar que um princípio valeria para um caso, não se concluiria que o mesmo resultado valesse para outro. Distinto seria o caso das regras, pois elas exigiriam que se fizesse exatamente como nelas estivesse ordenado.

No fundo, na era pós-positivista, com a utilização das teoria(s) da argumentação jurídica, os hard cases passam a ser resolvidos a partir de ponderações de princípios, ou seja, a partir do momento em que eles entram em conflito, devem ser ponderados. "O problema é saber como é feita essa 'escolha'” (STRECK, 2007, p. 180). Observa-se que a ponderação evidencia o retorno ao decisionismo, que para o positivismo (Kelsen e Hart) era resolvido pela delegação ao juiz. Dessa forma, a presença da filosofia da consciência no procedimentalismo de Alexy é evidente. Até mesmo Habermas e seus adeptos criticam a teoria da "ponderação discricionária" de Alexy.

Entre os adeptos da teoria habermasiana que criticam a teoria alxyniana, Marcelo Andrade Cattoni de Oliveira faz importante análise de julgado brasileiro, denominado de "Caso Ellwanger" decidido pelo Supremo Tribunal Federal. ${ }^{19}$

No HC n. 82.424-2, vários Ministros do Supremo Tribunal Federal procuraram compreender o caso a partir de uma suposta colisão entre os valores: liberdade de expressão e dignidade da pessoa humana. O caso Elwanger envolve um editor de Porto Alegre que teria publicado livros de cunho antissemita. Em síntese, as advogados da parte acusada alegaram que embora as publicações fossem reconhecidamente discriminatórias aos judeus, não poderiam ser consideradas racistas. Sendo assim, o crime já estaria prescrito, ensejando a concessão do HC.

Considerando os votos dos Ministros Gilmar Ferreira Mendes e Marco Aurélio, percebe-se que os dois chegaram a conclusões diferentes, mas ambos utilizaram a "ponderação" proposta por Alexy. Refletindo a posição majoritária, Mendes refere-se à liberdade de expressão, por se tratar de uma violação injustificável à dignidade humana; assim, propugna pela não concessão do HC. Já o Ministro Marco Aurélio reporta-se à promoção da democracia, do bem-estar e de uma cultura pluralista, argumentando ser proporcionalmente melhor que a opinião pública escolha e decida sobre o tema.

No Caso Ellwanger, todavia, não se deve discutir em termos de colisão entre valores, mas, sim, julgar se houve, diante do caso concreto, crime de racismo ou não, isso 
tudo à luz da Constituição Federal de 1988. Nesse sentido, é possível chegar-se à conclusão de que houve racismo, sem que para isso se tenha que renunciar ao caráter deontológico do Direito. ${ }^{20}$

$\mathrm{Na}$ verdade, não se deve ponderar valores, nem em abstrato, nem em concreto. Por isso, para a hermenêutica fenomenológica, o princípio da proporcionalidade não tem o mesmo significado que tem para a teoria da argumentação, sendo considerado como uma metáfora, isto é, um modo de explicar que cada interpretação deve obedecer a uma reconstrução integrativa do direito, para evitar interpretações arbitrárias Assim, a “'era dos princípios' não é [...] um plus axiológico-interpretativo que veio para transformar o juiz [...] em superjuiz que vai descobrir os "valores ocultos" no texto, agora auxiliado/liberado pelos princípios” (STRECK, 2007, p. 188-189). A hermenêutica heideggeriana-gadameriana, de forma nenhuma, dá margem a decisionismos.

Em outras palavras, o princípio acaba por desvelar-se na regras. Ainda com relação aos princípios é importante salientar a doutrina de Ronald Dworkin, em que o autor americano se mostra totalmente contrário a arbitrariedades, sendo que a garantia contra decisionismos está no acesso a uma moralidade institucional. ${ }^{21}$ Antes de sustentar que a distinção "lógica" entre regras e princípios, para Dworkin, estaria no fato de que a regra se define na base do "tudo ou nada”, deve-se perceber que ele está inserido na common law e desenvolve a teoria da resposta correta. Mais ainda, Dworkin não faz a cisão entre interpretar e aplicar, tampouco admite dedutivismos; logo, não se pode colocá-lo na mesma seara das teorias discursirvo-argumentativas.

Na hermenêutica filosófica existe uma antecipação de sentido que se dá na aplicação, porque não há cisão entre interpretar e aplicar. Trata-se de trazer a resposta correta como a verdadeira, no sentido hermenêutico, como condições de possibilidades a partir das quais é possível desenvolver-se a ideia do que significa fundamentar e justificar (STRECK, 2007, p. 412).

Não há como se vislumbrar um Estado Democrático, sem o resgate de decisões conteudísticas que resgatem a efetividade dos direitos fundamentais do cidadão. E esse vir-à-fala traz o sentido da metáfora da resposta correta, porque é apenas na aplicação que se leva a sério a jurisdição constitucional.

\section{CONSIDERAÇÕes FINAIS}

Por derradeiro, se pode afirmar, nas pegadas deixadas por Sísifo até o alto da montanha, que a (re)construção do caminho e a (re)elaboração da trajetória até a "condenação" final, dependem de conjunturas que, necessariamente, envolvem a vontade humana. Isso porque o homem é um ente privilegiado ou um ser para possibilidades, que serão alcançadas no decorrer do tempo. Da mesma forma que a lenda de Sísifo está relacionada com fatos e tempo, o Direito, entendido como uma ciência aplicada às relações sociais, não deve jamais se afastar da concretude da história humana. Por isso, a hermenêutica 
da faticidade busca o verdadeiro, entendido como uma metáfora no sentido da busca pela resposta hermeneuticamente adequada à Constituição.

Salienta-se que de forma alguma esta resposta ou verdade deve ser entendida como absoluta, no sentido metafísico aristotélico-tomista da antiguidade, ou com o sentido iluminista da modernidade. A Nova Crítica do Direito está para além do caráter lógico-argumentativo das teorias discursivas/argumentativas, ligando-se ao mundo prático, ao círculo hermenêutico e à diferença ontológica. O "caso concreto" somente pode ser entendido a partir da reposta adequada à faticidade e à historicidade, estabelecendo-se, assim, a impossibilidade de separação entre questão de fato e questão de direito.

Dessa maneira, a hermenêutica fenomenológica busca em discursos decisórios o sentido material do constitucionalismo e dos direitos fundamentais. O Poder Judiciário, em tempos de neoconstitucionalismo, pode ser entendido como um órgão que possibilita o desvelar do sentido "democrático", pois a democracia não se manifesta de forma indireta por meio de representantes, mas possibilita aos cidadãos ou às entidades de classe o acesso à jurisdição. Todavia, deve-se atentar para o fato de que esse Poder Jurisdicional de forma alguma deve ser arbitrário, baseado em valores próprios inautênticos ou juízos de "ponderação".

É imprescindível que se superem os paradigmas aristotélico-tomista e da filosofia da consciência, ainda impregnados na jurisdição constitucional brasileira. Para isso, relacionando com o que Stein e Streck afirmam sobre necessidade da retomada da filosofia pelo direito, com a denominação filosofia no direito, pode-se também pensar a filosofia na Constituição, ou seja, uma "sabedoria" presente na sua aplicabilidade em sociedade, naquilo que Hesse denominou de vontade de Constituição.

Nesse contexto, através de discursos decisórios atentos ao verdadeiro exame dos elementos antecipatórios dos enunciados aplicados aos casos concretos, propõe-se chegar à efetividade da Constituição, elo conteudístico que une Estado e sociedade. Talvez, se possa retornar a epígrafe deste artigo, que trata da "filosofia do absurdo", desenvolvida por Camus. O "absurdo" confronto entre o irracional e o desejo desvairado de clareza presente no mais profundo ser humano. Camus (2006, p. 35) resgata o espetáculo da vida e do mundo, para questionar as certezas absurdas e para reafirmar a relação homem/mundo. Com efeito, não há como fugir dessa relação, residindo também nela a importância da busca pela efetividade da Constituição, norma fundamental de proteção aos direitos do homem. 
166 : A FILOSOFIA HERMENÊUTICA PARA UMA JURISDIÇÃO CONSTITUCIONAL DEMOCRÁTICA

\section{NOTAS}

1 Teoria pesquisa e desenvolvida por Lenio Luiz Streck, na obra Verdade e consenso.

2 No decorrer deste artigo serão abordadas algumas pontuações a respeito da filosofia hermenêutica desenvolvida por Martin Heidegger e da hermenêutica filosófica trabalhada por Hans-Gerg Gadamer, no sentido de auxiliar a fase atual em que se encontra a jurisdição constitucional.

3 Não há que se confundir o Estado (Moderno) com outra experiência que não seja a da modernidade, erigida como tal a partir do século XVI, sendo suas experiências anteriores tidas como formas estatais pré-modernas (Bolzan de MORAIS; STRECK, 2006)

4 Para Jorge Miranda, o Direito Público passou por uma revolução copernicana, ou seja, a passagem de uma fase em que as normas constitucionais dependiam de uma ação do legislador, para uma fase em que se aplicam diretamente nas situações concretas da vida, através do aparecimento de uma justiça constitucional legitimada (MIRANDA apud STRECK, 2004, p. 18).

5 Para aprofundar o estudo, consultar as obras do professor Lenio Luiz Streck.

6 Heidegger critica a ontologia tradicional, preocupada unicamente com os entes, e que postulava a hierarquia dos níveis de entidade: natureza inanimada, plantas, animais, homem, etc. A ontologia fundamental foi um modo "transicional" de superar a ontologia tradicional, por meio do questionamento do seu "fundamento" - o outro lado da diferença ontológica - o ser. Assim, como a ontologia tradicional projeta os entes para a entidade, Heidegger projeta a entidade como ser para a sua verdade (INWOOD, 2002, p.132).

7 É importante ressaltar que o termo historicismo pode ter mais de uma significação, chegando a ser ambíguo. Relaciona-se com o homem, a história ou a razão (SCHNÄDELBACH, 1991, p. 49-52).

8 Certas palavras alemães parecem significar tudo. Uma delas é o da. Ela significa "lá" e "aî". Com o prefixo de sein, "ser", ela forma dasein, "ser aí, presente, disponível, existir (Inwood, 2002, p. 29). A compreensão é entendida como estrutura ontológica do Dasein (ser-aí ou presença), não sendo esse modo uma "propriedade do ser”, mas, sim, o próprio ser. Heidegger situa a questão da ontologia fundamental no sentido do ser; a clarificação resulta no único ente que compreende o ser, que é o homem (Dasein), o estar-aí, que é o ser-no-mundo, que é o cuidado (sorge); o cuidado é temporal (zeitlich) (STRECK, Lenio Luiz, 2007, p. 178). Salienta-se que os caracteres do Dasein levam o nome de existenciais, já as categorias são determinações do ser dos entes não conformes com o Dasein (VATTIMO, 1996, p. 26).

9 Para Heidegger, deve-se traduzir a palavra alétheia por “desvelamento" em lugar de "verdade”, pois essa tradução não é somente mais literal, ela compreende a indicação de repensar mais originalmente a noção corrente de verdade como conformidade de enunciação, no sentido, ainda incompreendido, do caráter de ser desvelado e do desvelamento do ente (STRECK, 2007, p. 178).

10 Íntegra da sentença envolvendo o jogador Richarlyson. Disponível em: <http://www1.folha.uol.com.br/ folha/esporte/ult92u317519.shtml>. Acesso em: 01 set 2007.

11 Idem.

12 Idem.

13 Para aprofundar o tema consular: Verdade e consenso. Constituição, hermenêutica e teorias discursivas. Da possibilidade à necessidade de respostas corretas em direito, de Lenio Luiz Streck (2007).

14 A origem da palavra vem do latim constitutio do qual deriva o verbo constituire, que significa instituir, fundar. (Sartori, 1992, p. 15). É importante destacar a distinção realizada por Canotilho entre o conceito antigo e moderno de constitucionalismo (CANOTILHO, 2002, p. 52-55)

15 Konrad Hesse, em seu livro A força normativa da Constituição, contrapõe-se à tese defendida por Ferdinand Lassalle, em 1863, para intelectuais e operadores da antiga Prússia. Hesse pretende demonstrar que o desfecho entre fatores reais de Poder e a Constituição não há de verificar-se em desfavor desta (HESSE, 1991; LASSALLE, 2001). 
16 O modelo de Constituição cultural é uma soma de atitudes, ideias, experiências, escalas de valores e expectativas subjetivas e correspondentes ações objetivas, dos cidadãos, das suas associações e dos órgãos estatais (VERDU, 1998, p. 21 273; HÄBERLE, 2000, p. 161).

17 A formulação do conceito de Constituição aberta deve-se a Peter Häberle, o qual afirma que a interpretação da Constituição é um processo aberto que envolve uma democracia de cidadãos. É importante sublinhar as dificuldades que a noção häberliana encontra em países como o Brasil, pois consoante Paulo Bonavides o método concretista da "Constituição aberta” demanda para uma eficaz aplicação a presença de sólido consenso democrático, base social estável, pressupostos institucionais firmes [...] fatores difíceis de achar nos sistemas políticos sociais de nações subdesenvolvidas [...] (HÄBERLE, 1997, p. 55; BONAVIDES, 2003, p. 516).

18 Sublinha-se que não é objeto deste artigo o aprofundamento dessa discussão.

19 Esse texto é disponibilizado pelo autor aos doutorandos da Unisinos, 2007.

20 Idem.

21 Para aprofundar o tema, consultar as obras de Ronald Dworkin: Levando o direito a sério (2002); O império do direito (1999); Uma questão de princípio (2000), entre outras.

\section{REFERÊNCIAS BIBLIOGRÁFICAS}

ALEXY, Robert. Teoria de los derechos fundamentales. Madrid: Centro de Estúdios Constitucionales, 1997. BRASIL, Supremo Tribunal Federal. HC n. 82. 424-2. Disponível em: <http://www.stf.gov.br>. Acesso em: 05.09.2007.

BRASIL, Supremo Tribunal Federal. MI n. 721-7. Disponível em: <http://www.stf.gov.br>. Acesso em: 05.06.2008.

BERCOVICI, Gilberto. Desigualdades Regionais, Estado e Constituição. São Paulo: Max Limonad, 2002.

BOLZAN DE MORAIS, José Luis; STRECK, Lenio Luiz. Ciência Política e Teoria do Estado. 5. ed. rev. e atual. Porto Alegre: Livraria do Advogado, 2006.

. Crise do Estado, Constituição e Democracia Política: a "realização" da ordem constitucional! E o povo... In: COPETTI, André; STRECK, Lenio Luiz; ROCHA, Leonel Severo; PEPE, Albano Marcos Bastos. Orgs. Constituição, sistemas sociais e hermenêutica: programa de pós-graduação em direito da Unisinos: mestrado e doutorado. Porto Alegre: Livraria do Advogado; São Leopoldo: Unisinos, 2006, p. 91-111. BONAVIDES, Paulo. Curso de direito constitucional. São Paulo: Malheiros, 2003.

BRANDÃO, Junito de Souza. Mitologia grega. Vol. II. Petrópolis: Vozes, 2000.

BULFINCH, Thomas. Trad.: David Jardim. O livro de ouro da mitologia. História de deuses e heróis. 29.ed. Rio de Janeiro: Ediouro, 2003.

CAMUS, Albert. O mito de Sísifo. 3.ed. Rio de Janeiro: Record, 2006.

CANOTILHO, J. J. Gomes. Direito Constitucional e teoria da Constituição. 6.ed. Coimbra: Almedina, 2002.

CITTADINO, Gisele. Pluralismo, direito e justiça distributiva. Elementos da filosofia constitucional contemporânea. 2.ed. Rio de Janeiro: Lumen Juris, 2000.

DEMO, Pedro. Metodologia científica em ciências sociais. 3.ed. São Paulo: Atlas, 1995, p. 247-257.

DWORKIN, Ronald. Levando o direito a sério. São Paulo: Martins Fontes, 2002.

. O império do direito. São Paulo: Martins Fontes, 1999.

Uma questão de princípio. São Paulo: Martins Fontes, 2000

GADAMER, Hans-Gerg. Verdade e método. 5.ed. São Paulo: Vozes, vol. 1., 2003.

GRONDIN, Jean. Introdução à hermenêutica filosófica. São Leopoldo: Unisinos, 1999.

HABERMAS, Jürgen. Direito e Democracia - entre faticidade e validade, I e II. Rio de Janeiro: Tempo Brasileiro, 1997.

HÄBERLE, Peter. Hermenêutica constitucional. A sociedade aberta dos intérpretes da Constituição: contribuição para a interpretação pluralista e "procedimental” da Constituição. Porto Alegre: Sergio Antonio Fabris, 1997. Fabris Ed, 2008 . Os problemas da verdade no Estado Constitucional. Trad.: Urano Carvelli. Porto Alegre: Sérgio Antonio 
168 : A FILOSOFIA HERMENÊUTICA PARA UMA JURISDIÇÃO CONSTITUCIONAL DEMOCRÁTICA

HÄBERLE, Peter. Teoria de la Constitución como ciencia de la cultura. Madrid: Editorial Tecnos, 2000.

HEIDEGGER, Martin. Carta sobre o humanismo. São Paulo: Editora Moraes, 1991. Que é metafísica? São Paulo: Nova Cultural, 1991.

. Ser e tempo. Petrópolis: Vozes, Parte I, 2002.

HESSE, Konrad. A força normativa da constituição. Porto Alegre: Sergio Antonio Fabris, 1991.

INSTITUTO HUMANITAS UNISINOS. Revista on line. Ano 2, n. 9, 18.03.2002. Disponível em:

<http://www.unisinos.br/ihu_online/uploadas/edições>. Acesso em: 12.08.2007.

INWOOD, Michael. Dicionário Heidegger. Rio de Janeiro: Jorge Zahar Editor, 2002.

Íntegra da sentença envolvendo o jogador Richarlyson. Disponível em: <http://www1.folha.uol.com.br/

folha/esporte/ult92u317519.shtml>. Acesso em: 01 set. 2007.

LASSALLE, Ferdinand. A essência da constituição. 6.ed. Rio de Janeiro: Lumen Juris, 2001.

MIRANDA, Pontes de. Comentários à Constituição de 1946. 4.ed. rev. e ampl. Rio de Janeiro: Borsoi, t. II, 1963.

MOREIRA, Vital. O futuro da Constituição. In: GRAU, Eros Roberto. GUERRA FILHO, Willis Santiago. Direito Constitucional. Estudos em homenagem a Paulo Bonavides. São Paulo: Malheiros, 2001, p. 314-318.

OLIVEIRA, Marcelo Andrade Cattoni. Coord. Jurisdição e hermenêutica constitucional. Belo Horizonte: Mandamentos, 2004

. O caso Ellwanger: uma crítica à ponderação de valores e interesses na jurisprudência recente do

Supremo Tribunal Federal. Texto disponibilizado pelo autor aos doutorandos da Unisinos 2007, para disciplina Hermenêutica, Interpretação e Linguagem, ministrada pelo professor Lenio Luiz Streck.

SAFRANSKI, Rüdiger. Heidegger. Um mestre da Alemanha entre o bem e o mal. Trad.: Lya Lett Luft. São Paulo: Geração Editorial, 2000.

SALDANHA, Nelson. Formação de uma teoria constitucional. Rio de Janeiro: Renovar, 2000.

SARTORI, Giovani. Elementos de teoria política. Madri: Alianza Editorial, 1992.

SCHNÄDELBACH, Herbert. Filosofía en Alemania, 1831-1933. Madrid: Colección Teorema, 1991.

STEIN, Ernildo. A Consciência da história: Gadamer e a hermenêutica. Disponível em: <http://www.cfh.ufsc.br/ wfil/gadamer.htm>. Acesso em: 12.08.2007. Aproximações sobre hermenêutica. Porto Alegre: Edipuc, 1996.

. Breves considerações históricas sobre as origens da filosofia no direito. Revista do Instituto de

Hermenêutica Jurídico. Porto Alegre: Instituto de Hermenêutica Jurídica, 2007, p. 97- 110.

. Pensar é pensar a diferença: filosofia e conhecimento empírico. Ijuí: UNIJUÍ, 2004.

STRECK, Lenio Luiz. HEIDEGGER, Marin. In: BARRETO, Vicente. Coord. Dicionário de filosofia do direito. São Leopoldo: Unisinos. Rio de Janeiro, 2006, p. 426-430.

. Hermenêutica Jurídica e $(m)$ crise: uma exploração hermenêutica da construção do direito. 7. ed. rev. e ampl. Porto Alegre: Livraria do Advogado, 2007. .Interpretando a Constituição: Sísifo e a tarefa do hermeneuta. Revista do Instituto de Hermenêutica Jurídico. Porto Alegre: Instituto de Hermenêutica Jurídica, 2007, p. 125-144. Forense, 2004 Jurisdição constitucional e hermenêutica: uma nova visão crítica do Direito. 2.ed. Rio de Janeiro:

. Verdade e consenso. Constituição, hermenêutica e teorias discursivas. Da possibilidade à necessidade de respostas corretas em direito. 2.ed. Rio de Janeiro: Lumen Juris, 2007.

TRIBE, Laurence; DORF, Michael. Trad.: Amarílis de Souza Birchal. Hermenêutica constitucional. Belo Horizonte: Del Rey, 2007.

VATTIMO, Gianni. Introdução a Heidegger. Lisboa: Instituto Piaget, 1996.

Valéria Ribas do Nascimento

Rua Duque de Caxias, 1900/203 Centro - 97015-190 Santa Maria - RS - Brasil valribaslaterra.com.br
MESTRE EM DIREITO PÚBLICO PELA

UNIVERSIDADE DE SANTA CRUZ DO SUL

DOUTORANDA EM DIREITO PÚBLICO PELA UNIVERSIDADE DO VALE DO RIO DOS SINOS

PROFESSORA DE DIREITO CONSTITUCIONAL DA FACULDADE DE DIREITO DE SANTA MARIA E UNISINOS

Advogada 